\title{
Pediatric nuclear medicine and pediatric radiology
}

\author{
Modalities, image quality, dosimetry and correlative imaging: new strategies
}

\author{
Isabel Roca-Bielsa • Marina Vlajković
}

Received: 6 February 2013 / Accepted: 6 February 2013

(C) Springer-Verlag Berlin Heidelberg 2013

To improve clinical practice is our daily duty as specialists in radiology and in nuclear medicine. When a clinician asks us to perform an imaging examination, we have to advise that clinician about the best test or imaging strategy to study the clinical problem. Risk-to-benefit ratio and the ALARA principle have to be weighed, as well as modality and cost.

Hybrid imaging is now the standard in nuclear medicine. The use of multimodality cameras such as SPECT/CT, $\mathrm{PET} / \mathrm{CT}$ and PET/MR has been revolutionary [1-4]. The key is finding the exact location of functional or metabolic lesions. But adding CT increases the dosimetry [5-7], requires more detailed knowledge of imaging anatomy and depends on collaboration between radiologists and nuclear medicine specialists. The level of expertise among imaging specialists (at least in pediatric nuclear medicine) varies too much. In some countries nuclear medicine is an independent specialty, and in other countries radiologists are in charge of nuclear medicine tests. Physicians-in-training in radiology and in nuclear medicine have to receive multimodality training [8-12]. And continuing education in both specialties is vital to ensure that senior specialists are well-versed in the latest techniques. In any case, imaging specialists must be able to discuss the options with referring clinicians and to advise them on the appropriate technique for each clinical situation.

Pediatric nuclear medicine can be performed in general nuclear medicine facilities or in dedicated pediatric nuclear medicine departments. The quality of the images has to be

\section{Roca-Bielsa $(\bowtie)$}

Department of Nuclear Medicine, Hospital General Universitari

Vall d'Hebron, Passeig Vall d'Hebron 119-129,

Barcelona 08035, Spain

e-mail: iroca@vhebron.net

M. Vlajković

Center of Nuclear Medicine, Faculty of Medicine,

University of Niš, Blvd dr Zorana Djindjića 48,

Niš 18000 , Serbia diagnostically excellent in pediatric nuclear medicine but superfluous scans must be avoided and doses must be as low as reasonably achievable and adjusted to each child according to international recommendations [7, 13-16]. These goals can be more easily reached in dedicated pediatric facilities.

Dose reduction remains important. Contrary to general opinion the radiation dose of most nuclear medicine scans is lower than that of many comparable radiologic studies. The most typical example is abdominal CT, which has a higher dose than the most frequent nuclear medicine studies. Another example is that two-thirds of the radiation dose from PET/CT is from the CT component [12-14]. In the latter case it is possible to perform a diagnostic CT scan during the PET/CT examination rather than a separate diagnostic CT scan. Or a lower-dose CT scan could be performed in a patient who has recently undergone a diagnostic $\mathrm{CT}$ scan. The best option for the future in pediatric oncology, however, is PET/MR. In bone scintigraphy or an MIBG scan, performance of an SPECT/CT scan significantly increases the radiation dose [15-17]. A possibility is to use a lower-dose nondiagnostic CT scan in these cases. And the best practice is to report together with the radiologist, comparing the SPECT and the $\mathrm{CT}$ or MR images frame-by-frame.

In many papers, correlative analysis of PET/CT images in children has been reported to be superior to separate analysis of CT and FDG/PET images. The term "correlative imaging" is the joint interpretation of different imaging modalities - CT, MR, US and scintigraphy [18]. This is the best example yet of why collaboration between radiologists and nuclear medicine physicians is so important.

\section{References}

1. London K, Stege C, Cross S et al (2012) 18F-FDG PET/CT compared to conventional imaging modalities in pediatric primary bone tumors. Pediatr Radiol 42:418-430 
2. Kaste SC (2011) PET-CT in children: where is it appropriate? Pediatr Radiol 41:509-513

3. Biermann M, Schwarzlmüller T, Fasmer KE et al (2013) Is there a role for PET-CT and SPECT-CT in pediatric oncology? Acta Radiol. doi:10.1258/ar.2012.120616

4. Goo HW (2011) Regional and whole-body imaging in pediatric oncology. Pediatr Radiol 41:S186-S194

5. Gelfand MJ (2010) Dose reduction in pediatric hybrid and planar imaging. Q J Nucl Med Mol Imaging 54:379-388

6. Delbeke D (2010) SNM general and hybrid imaging guidelines. J Nucl Med 51:14N

7. Delbeke D, Coleman RE, Guiberteau MJ et al; Society of Nuclear Medicine (SNM) (2006) Procedure guideline for SPECT/CT imaging 1.0. J Nucl Med 47:1227-1234

8. Cuocolo A, Adam A (2007) The "white paper of the European Association of Nuclear Medicine (EANM) and the European Society of Radiology (ESR) on multimodality imaging": a message from the EANM and ESR presidents. Eur J Nucl Med Mol Imaging 34:1145-1146

9. Bischof Delaloye A, Carrió I, Cuocolo A et al (2007) White paper of the European Association of Nuclear Medicine (EANM) and the European Society of Radiology (ESR) on multimodality imaging. Eur J Nucl Med Mol Imaging 34:1147-1151

10. Gourtsoyiannis N, McCall I, Reiser M et al (2007) White paper of the European Society of Radiology (ESR) and the European Association of Nuclear Medicine (EANM) on multimodality imaging. Eur Radiol 17:1926-1930
11. Stegger L, Schäfers M, Weckesser M et al (2008) EANM-ESR white paper on multimodality imaging. Eur J Nucl Med Mol Imaging 35:677-680

12. Nievelstein RA, Quarles van Ufford HM, Kwee TC et al (2012) Radiation exposure and mortality risk from CT and PET imaging of patients with malignant lymphoma. Eur Radiol 22:1946-1954

13. Stauss J, Franzius C, Pfluger T et al (2008) Guidelines for $18 \mathrm{~F}$ FDG PET and PET-CT imaging in paediatric oncology. Eur J Nucl Med Mol Imaging 35:1581-1588, Erratum in: Eur J Nucl Med Mol Imaging 2008;35:2140

14. Lassmann M, Biassoni L, Monsieurs M et al (2007) The new EANM paediatric dosage card. Eur J Nucl Med Mol Imaging 34:796-798

15. Fahey FH, Treves ST, Adelstein SJ (2012) Minimizing and communicating radiation risk in pediatric nuclear medicine. J Nucl Med Technol 40:13-24

16. Bombardieri E, Giammarile F, Aktolun C et al (2010) 131I/123Imetaiodobenzylguanidine (mIBG) scintigraphy: procedure guidelines for tumour imaging. Eur J Nucl Med Mol Imaging 37:24362446

17. Walter F, Czernin J, Hall T et al (2012) Is there a need for dedicated bone imaging in addition to $18 \mathrm{~F}-\mathrm{FDG}$ PET/CT imaging in pediatric sarcoma patients? J Pediatr Hematol Oncol 34:131-136

18. Furth C, Denecke T, Steffen I et al (2006) Correlative imaging strategies implementing CT, MRI, and PET for staging of childhood Hodgkin disease. J Pediatr Hematol Oncol 28:501-512 